\title{
Inhaltsverzeichnis
}

Andreas Hetzel

Vorwort

\section{Einflüsse und Debatten}

Ingo Pohn-Lauggas

Integraler Staat und radikale Demokratie. Hegemonie und Staatsmacht bei

Gramsci und Laclau/Mouffe

Ingo Elbe

Politische Macht, Faschismus und Ideologie. Ernesto Laclaus

Auseinandersetzung mit Nicos Poulantzas

Liza Mattutat/Felix Breuning

Unfreiwillig mit Schmitt. Die Rezeption Carl Schmitts in der

Demokratietheorie Chantal Mouffes

\section{Zur staatstheoretischen Relevanz radikaldemokratischen Denkens}

Anja Rüdiger

Hegemonie als ethische Praxis. Zu den Strategien sozialer Bewegungen

im neoliberalen Staat

Manon Westphal

Reform und Innovation als Strategien einer radikaldemokratischen Kritik staatlicher Institutionen

Alfred Schäfer

Bildung und Humankapital. Zur Interdiskursivität als hegemoniale

Strategie staatlicher Steuerungsrhetorik 


\section{Konfigurationen von Staatlichkeit heute}

\section{Simon Bohn}

Rechtspopulismus und radikale Demokratie. Eine Verhältnisbestimmung in Anbetracht der Protestbewegung PEGIDA

Joscha Wullweber

Staat und Ökonomie als Diskursformationen

Susanne-Verena Schwarz

Agonistische Öffentlichkeiten bei Chantal Mouffe: Zwischen lebendiger Demokratie und Populismus

\section{Stefanie Wöhl}

Demokratie vs. multiple Krisen - Eine hegemonietheoretische

Perspektive auf die Europäische Union

Verzeichnis der Beitragenden 